\title{
Explanations for cultural differences in thinking: Easterners' dialectical thinking and Westerners' linear thinking
}

\section{Hiroshi Yama, Norhayati Zakaria}

\begin{tabular}{|c|c|}
\hline Citation & Journal of Cognitive Psychology, 31(4); 487-506 \\
\hline Issue Date & 2019-06-04 \\
\hline Type & Journal Article \\
\hline Textversion & Author \\
\hline 概要 & 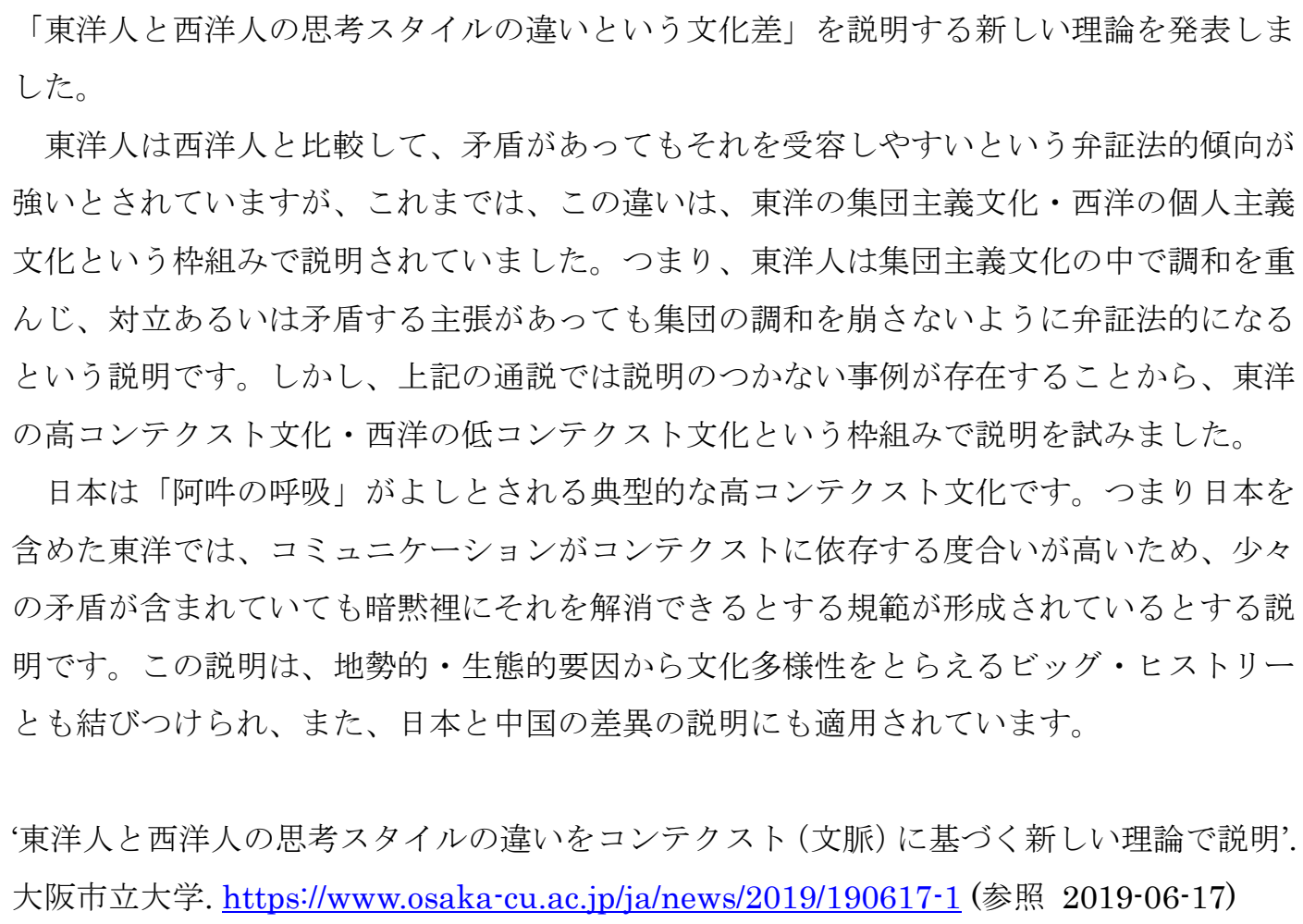 \\
\hline Rights & $\begin{array}{l}\text { This is an Accepted Manuscript of an article published by Taylor \& Francis in } \\
\text { Journal of Cognitive Psychology on 04/06/2019, available online: } \\
\text { https://doi.org/10.1080/20445911.2019.1626862. }\end{array}$ \\
\hline DOI & $10.1080 / 20445911.2019 .1626862$ \\
\hline
\end{tabular}

\section{Self-Archiving by Author(s) Placed on: Osaka City University}

Hiroshi Yama \& Norhayati Zakaria (2019) Explanations for cultural differences in thinking: Easterners' dialectical thinking and Westerners' linear thinking, Journal of Cognitive Psychology, 31. 487-506. DOI: 10.1080/20445911.2019.1626862 


\title{
Explanations for cultural differences in thinking: Easterners' dialectical thinking and Westerners' linear thinking
}

\author{
Hiroshi Yama ${ }^{1}$ and Norhayati Zakaria ${ }^{2}$ \\ ${ }^{1}$ School of Literature and Human Sciences, Osaka City University, Sumiyoshi, Osaka \\ 558-8585, Japan \\ ${ }^{2}$ Faculty of Business and Management, University of Wollongong in Dubai, Dubai, \\ 20183, United Arab of Emirates
}

\section{Acknowledgement}

This research has been supported by a CHORUS grant from the French Ministry of Research and the Japanese Society for the Promotion of Science and by a grant-in-aid from the Japanese Society for the Promotion of Science (No. 23330199 and No. 18K03010). We would like to expresses our gratitude to Ken I. Manktelow for his comments on the earlier draft of this paper and three anonymous reviewers for their comments on the manuscript.

Correspondence concerning this article should be addressed to Hiroshi Yama. School of Literature and Human Sciences, Osaka City University. Sumiyoshi, Osaka 558-8585, JAPAN 
Contact: yama.hiroshi1204@gmail.com

\begin{abstract}
Since Easterners' naïve dialectical thinking, which is contrasted with Westerners' linear thinking, introduced, many cross-cultural studies on human thinking have been conducted, and explanations for the cultural differences have been proposed. First, after examining the robustness of these cultural differences, two existing explanations are discussed in this paper. The first is based on the distinction between Westerners' analytic cognition and Easterners' holistic cognition. This is related to the distinction between Westerners' independent self and Easterners' interdependent self. The second is based on the philosophical tradition of China's Taoism, Confucianism, and Buddhism, which is contrasted with that of Ancient Greece. Second, we propose a new explanation based on the distinction between Westerners' low-context culture and Easterners' high-context culture. Finally, we show that this distinction can be based on socioecological approaches, and it is expected to explain the cultural differences between the Chinese and Japanese.
\end{abstract}

Keywords: cultural difference, dialectical thinking, low-context culture and high-context culture, socioecological approach 
According to the ideas of 20th-century psychology (e.g., Chomsky, 1957), the human mind is universal across cultures. Hence, cultural differences were not viewed as important and were described in terms of culturally specific behavior as a response to a culturally specific stimulus. However, recent cross-cultural studies have begun to abandon this universality assumption, instead accepting the interactive view that the human mind has been shaped by its interaction with culture (Markus \& Kitayama, 1991; Na, Grossmann, Varnum, Kitayama, Gonzalez, \& Nisbett, 2010; Nisbett, Peng, Choi, \& Norenzayan, 2001; Varnum, Grossman, Kitayama, \& Nisbett, 2010). Conversely, a revised view that the mechanism of adaptation is universal is introduced to explain cultural differences in terms of cultural adaptation (e.g., Atran \& Medin, 2008; Norenzayan \& Heine, 2005).

In this paper, we focus on the cultural differences in thinking between Westerners and Easterners and discuss how these differences can be explained. As discussed in the next section, it has been demonstrated that Westerners' thinking style is linear, whereas Easterners' thinking style is intuitive or dialectical (e.g., Nisbett, et al., 2001; Peng \& Nisbett, 1999). The reason why the term "style" is used is that it is still uncertain how deep-rooted these differences are in terms of whether they are based on different systems or just reflect different preferences.

We introduce and examine the existing explanations for these cultural differences in thinking. One is based on the distinction between Westerners' 
individualist culture and Easterners' collectivist culture (e.g., Nisbett et al., 2001). The other is based on philosophical traditions (e.g., Spencer-Rodgers, Boucher, Mori, Wang, \& Peng, 2009). We also introduce a new explanation, which was originally proposed to explain the differences in communication style: the high-context vs. low-context dimension (Hall, 1976). Finally, we examine whether this new explanation can be developed as a socioecological theory.

\section{WESTERNERS' LINEAR THINKING VS. EASTERNERS' DIALECTICAL}

\section{THINKING}

Sometimes, we cannot decide whether we should resolve or accept a contradiction. For example, you might find that some people are in favor of globalization, while others are against it. How does one formulate an opinion — that is, to either accept one side or agree with both? In this paper, these differences in thinking style are examined and discussed within the framework of cultural influence. It has been demonstrated that Westerners are inclined to think linearly, whereas Easterners are not (Norenzayan, Smith, Kim, \& Nisbett, 2002; Peng \& Nisbett, 1999). For example, Norenzayan et al. (2002) reported that when asked which one of two groups a target object was similar to, Americans tended to focus on a single property for the grouping, whereas Koreans did not. Americans preferred linear (the terms "formal" and/or "rule- 
based" were used in Norenzayan et al.'s original paper) reasoning, focusing on a single property, whereas Koreans preferred similarity-based, nonlinear ("intuitive" was used in their original paper) reasoning, which the group members thought of as having a family resemblance. This tendency was confirmed by their other experiment on categorical inference (Norenzayan et al., 2002). For instance, Koreans were less inclined than Americans to accept the conclusion that "all penguins have an ulnar artery"; this was based on the premise that "all birds have an ulnar artery," because penguins are not typical birds. In short, Easterners, including Koreans, consider not only a single property for linear thinking but also other properties, such as "cannot fly," for intuitive thinking.

In place of the term Easterners' intuitive thinking, many researchers accept the term Easterners' dialectical thinking. Similarly, in place of the term Westerners' rulebased thinking, the term Westerners' linear thinking is accepted by many researchers. The term "rule" can be defined in the form of the conditional if $p$ then $q$, and, thus, the term "rule-based" implies that people apply this formal rule for thinking logically. However, because Westerners' thinking style does not correspond to logical thinking in the strict sense, we use the term "linear thinking." In their pioneering work, Peng and Nisbett (1999) proposed that the essential property of Easterners' thinking is dialecticism, which is contrasted with Westerners' linear thinking. They found that the thinking style of Chinese people was more dialectical than that of Americans. They 
conducted several cross-cultural experiments to compare Chinese with Americans.

Compared to the Americans, the Chinese were less sensitive to and more accepting of contradictory proverbs, such as "too humble is half proud." This shows that the Chinese have a stronger tolerance for contradiction; in other words, it indicates that the Chinese prefer dialectical thinking. Furthermore, Peng and Nisbett (1999) demonstrated that the Chinese participants rated their agreement with two contradictory statements more moderately when these statements were presented together than when either of the statements was presented individually. This trend was not observed in the data related to the Americans. These results indicate that the Chinese are more likely to take the middle way when they encounter contradictory opinions.

This distinction has been discussed in terms of the contrast between Westerners' analytic cognition and Easterners' holistic cognition (Nisbett, Peng, Choi, \& Norenzayan, 2001). Linear thinking is a form of analytic cognition, whereas dialectical thinking is a form of holistic cognition. According to Nisbett et al.'s (2001) definition, analytic cognition implies detachment of the object from its context, a tendency to focus on the attributes of the object to assign it to a category, and a preference for using rules about categories to explain and predict the object's behavior. In contrast, holistic cognition is oriented to the context or the field as a whole, attention to relationships between a focal object and the field, and a preference for explaining and predicting events on the basis of such relationships. 
The distinction between linear and dialectical thinking is one of the four dimensions of the analytic/holistic contrast. Using questionnaires, these four dimensions are, in effect, identified as four factors (Choi, Koo, \& Choi, 2007). The first factor to be discussed is causal attribution or causal inference. It is proposed that Easterners make more situational attributions, whereas Westerners make more dispositional attributions (Choi, Dalal, Kim-Prieto, \& Park, 2003; Choi \& Nisbett, 1998; Choi, Nisbett, \& Norenzayan, 1999; Morris \& Peng, 1994). The second factor emphasizes the use of rules, which is the focus of this paper. Westerners are inclined to use linear thinking, whereas Easterners are more apt to use dialectical thinking (Buchtel \& Norenzayan, 2008; Peng \& Nisbett, 1999; Spencer-Rodgers et al., 2009). The third factor focuses on the perception of change (Ji, 2008). Ji, Nisbett, and Su (2001) reported that the Chinese predicted changes more often than the Americans. Fourth, in the Westerners' analytic style of cognition, attention tends to be oriented to the object on which people are focusing, whereas the holistic style of Easterners tends to focus attention on not only an object itself but also on the context in which it is embedded (Ji, Peng, \& Nisbett, 2000; Masuda \& Nisbett, 2001).

What does the distinction between Westerners' linear thinking and Easterners' dialectical thinking mean? Generally, dialectical thinking is focused on how an individual perceives conflicting concepts to develop a comprehensive point of view. However, there have been different kinds of dialectics (e.g., Wong, 2006). The Hegelian 
dialectic is the best known among them. According to Hegel, dialecticism is defined as an inference in which a synthesis is inferred from a thesis and its antithesis. Thus, dialecticism is expected to produce a higher-level resolution where there are some opinions that contradict each other. This is in contrast to propositional logic, which does not allow contradiction. Dialectical thinking accepts contradiction and can, thus, be illogical while it can be seen as a higher-level form of thinking beyond the dichotomy of propositional logic.

However, Spencer-Rodgers, Williams, and Peng (2010) proposed that Easterners' dialecticism is neither poor illogical thinking nor higher-level thinking but what they call "naïve dialecticism," which has three aspects. In fact, Peng and Nisbett (1999) had already pointed out these three principles of naïve dialecticism:

(1) The principle of contradiction

Because of the interconnectedness of things, and the ever-changing world, paradoxes and contradictions arise constantly. Two opposing propositions may both be true, and opposites are only apparent.

(2) The principle of change

The universe is in flux and is changing constantly; therefore, the concepts that reflect it must also be fluid. Apparent stability is a signal of likely change.

(3) The principle of holism

Nothing exists in isolation; everything is connected. 
Easterners' naïve dialecticism consists of folk beliefs and is a lay theory that people have acquired through their rich cultural practices. Paletz, Bogue, MironSpektor, and Spencer-Rodgers (2018) pointed out two differences between Hegelian dialecticism and Easterners' naïve dialecticism. The first difference is related to the form of cognitive style. As mentioned, naïve dialecticism is a lay theory of thought and a culturally influenced set of assumptions. Conversely, Hegelian dialecticism was developed as a philosophical theory and has many different forms that are applied for various purposes, respectively. The second difference is found in the approach to contradiction. Hegelian dialecticism emphasizes synthesis; its aim is to create a synthesized solution. However, naïve dialecticism does not emphasize the solution but, rather, tolerance and acceptance of contradiction. In this sense, there is no aim to resolve contradiction in East Asian philosophy (Wong, 2006). Furthermore, Peng and Nisbett (1999) refer to Westerners' linear thinking. It appears to simulate the process that formal logic prescribes, but it is also a lay theory based on formal logic that has three principles: identity, non-contradiction, and the excluded middle.

These claims have been supported by many studies, which will now be reviewed. In Easterners' dialectical thinking, the tendency to consider two contradictory possibilities was observed in a cross-cultural study on hindsight bias. Yama, Manktelow, Mercier, Van der Henst, Do, Kawasaki, and Adachi (2010) confirmed that hindsight bias was stronger among Easterners than Westerners (e.g., Choi \& Nisbett, 2000) in a study 
with Japanese, Korean, British, and French participants. The Easterners were more inclined to think dialectically when they met a plausible outcome from a vignette and an unexpected outcome, while Westerners' judgment was less affected by the unexpected outcome.

Their claims are also supported by cross-cultural studies on self-concept. Spencer-Rodgers et al. (2009) investigated cultural differences in self-concept. They invented a questionnaire, which they called the Dialectical Self Scale (DSS). It consists of 32 items and includes statements such as "When I hear two sides of an argument, I often agree with both" and "I often find that things will contradict each other." It was invented to measure the individual degree of naïve dialecticism and, thus, the individual ontological view of the world, which is either contradictory or consistent. It includes items to measure the tendency of individuals to accept opposing elements (e.g., goodbad) as coexisting in their minds, as well as the individual's belief that the world is full of changes. Their finding that the DSS scores were higher among Easterners than Westerners supported the claim by Peng and Nisbett (1999). In other words, Easterners have a more dialectical self-concept than Westerners and hold the ontological view that the world is full of contradictions. Furthermore, Spencer-Rodgers, Peng, Wang, and Hou (2004) found that Chinese gave more conflicting responses in their self-evaluations than Americans. In other words, Chinese respondents' self-evaluations were both positive and negative (Boucher, Peng, Shi, \& Wang, 2009). This tendency toward dialecticism 
was also confirmed in regard to affect and emotion (e.g., Bagozzi, Wong, \& Yi, 1999). For example, Miyamoto, Uchida, and Ellsworth (2010) reported that Japanese were more likely to have mixed emotions than Americans, especially in pleasant situations. The Japanese experience slight sadness even when they feel happy. Similarly, MaKellams, Spencer-Rodgers, and Peng (2011) reported that Easterners have mixed feelings and evaluations not only about themselves but also about the groups to which they belong. As shown in one of the three principles of naïve dialecticism, change is also the key aspect of Easterners' dialecticism. Regarding this, Ji et al.'s (2001) finding that Chinese predicted changes more than Americans supports the claim made by Peng and Nisbett (1999), and Spencer-Rodgers, Williams et al. (2010) that Easterners are naively more dialectical than Westerners.

Although Peng and Nisbett (1999) showed that Easterners are more likely to take the middle way, their result regarding Chinese dialectical judgment was found only when contradictory statements were presented together. Hence, this cultural difference is not robust. Wong (2006) pointed out that Easterners' dialectical thinking does not mean that people take the middle way. Actually, Mercier, Zhan, Qu, Lu, and Van der Henst (2015) conducted a replication of Peng and Nisbett (1999) with French and Chinese participants, but neither group took the middle-way resolution when confronted with a pair of contradictory statements. Mercier, Yama, Kawasaki, Adachi, and Van der Henst (2012) found that neither French nor Japanese participants took the middle-way 
resolution when they received advice that opposed their own opinions. Both French and Japanese maintained their opinions.

The cross-cultural study conducted by Zhang, Galbraith, Yama, Wang, and Manktelow (2015) confirmed the above findings. They reported that the mean DSS scores of the Japanese and Chinese respondents were higher than those of the British participants. This result replicated those obtained in the studies conducted by SpencerRodgers et al. (2004, 2009) in the sense that the mean scores of Easterners were higher than those of Westerners. However, when their participants were given pairs of opposite opinions and were asked to rate how strongly they agreed with each of the pair, Easterners did not show more dialectic responses than the British. Easterners did not show a stronger tendency than Westerners to agree with nor disagree with both. Although Easterners believe that when they hear two sides of an argument, they often agree with both, in effect, they do not necessarily make a dialectical decision.

Therefore, the target cultural differences in thinking that this paper aims to explain are related to the naïve dialecticism and the individual ontological view of the world. In other words, compared to Westerners, Easterners have a stronger tendency to view the world as contradictory and, thus, interpret their thoughts as being composed of positive and negative aspects in their cultural practices. However, Friedman, Chen, and Vaid, 2006 (2006) did not replicate Peng and Nisbett's (1999) results using contradictory proverbs. Both Chinese and Americans preferred dialectical proverbs to 
non-dialectical ones and judged the dialectical type as wiser. Despite this doubt, the results on Easterners' stronger tendency of naïve dialecticism are robust (e.g., SpencerRodgers et al., 2009). Hence, we introduce the explanations for these cultural differences.

\section{EXISTING EXPLANATIONS FOR THE CULTURAL DIFFERENCES IN}

\section{THINKING}

We go further by introducing and examining the existing explanations for the cultural differences in thinking. Two kinds of explanations for these differences between Westerners and Easterners have been proposed. The first is based on the distinction between Westerners' individualist culture and Easterners' collectivist culture, and/or the distinction between Westerners' independent self and Easterners' interdependent self. The second is based on philosophical tradition; it assumes that there are influences from Ancient Greek philosophy on Westerners' linear thinking and from Ancient Chinese philosophy on Easterners' dialectical thinking.

\section{An explanation based on Westerners' individualist culture and Easterners' collectivist culture}

Nisbett et al. (2001) did not aim to explain the cultural differences between Westerners' 
linear thinking and Easterners' dialectical thinking specifically but provided an explanation for the distinction between Western analytic and Eastern holistic cognition. For their explanation, they used the cultural value dimensions that underlie individualist and collectivist cultures. In the long history of culture, it has been claimed that Western people have established a more individualist culture, whereas Eastern people have developed a more collectivist culture (Hofstede, 1980; Triandis, 1995). They discussed how each cognitive style adapts to its own cultural type. We regard culture as a hypothetical construct used to explain people's behavior and describe social patterns. According to Triandis (1995), individualism is defined as a social pattern that consists of loosely linked individuals who view themselves as independent of collectives (family, coworkers, tribe, and nation); are primarily motivated by their own preferences, needs, rights, and the contracts they establish with others; prioritize their personal goals over those of others; and emphasize rational analyses of the advantages and disadvantages of associating with others. Collectivism is defined as a social pattern that consists of closely linked individuals who see themselves as parts of one or more collectives, are primarily motivated by the norms of and duties imposed by these collectives, are willing to prioritize the goals of these collectives over their own personal goals, and emphasize their connectedness to members of these collectives. Nisbett et al. (2001) proposed two different routes of explanation for the cultural differences in thinking. Both explanations are based on the distinction between 
Westerners' individualist culture and Easterners' collectivist culture, and they emphasize the importance of group harmony in a collectivist culture. The first emphasizes the direct influence of culture on one's style of thinking. Focusing on contradiction, Nisbett et al. agree with Peng and Nisbett (1999), who argue that a dialectical resolution of contradiction by finding a middle way is adaptive in the Chinese tradition and has been shaping the tacit ontology and epistemology of Easterners. They suggest that dialectics can be seen as a cognitive tool that was developed to deal with social conflict. This is adaptive in a collectivist culture, in which people seek group-harmony. On the contrary, the judgment based on dichotomy, which is a tool for avoiding contradiction, is not adaptive in a collectivist culture. The second route is to view the styles of thinking as an aspect of the distinction between analytic and holistic cognition. If people live in a culture in which they have to belong to a group and have to put the group's goals, such as keeping group harmony, before their own (collectivist culture), they have to pay attention not only to the object itself but also to its contextual information in order to maintain the harmony of their collectives. Holistic cognition and thought are useful for dialectics because people have to take numerous situational elements and factors into consideration to make a decision in this way. However, as discussed in the previous section, it is doubtful whether Easterners are more likely to take the middle way than Westerners. Hence, it is very plausible that the second route of explanation is not needed. 
Both explanations are from a group-level (individualism/collectivism) to an individual-level cognitive style. However, as with the first route of explanation, Varnum et al. (2010) proposed an explanation at the individual level: from Westerners' independent self to analytic cognition and from Easterners' interdependent self to holistic cognition. The self is the medium between culture and cognitive style. It has been proposed that Easterners have a stronger attitude and orientation toward sociability and interdependence than Westerners in a collectivist culture. Markus and Kitayama (1991) connected the distinction between individualism and collectivism to two kinds of selves. They argued that Westerners have an independent self, whereas Easterners have an interdependent self. According to them, Westerners are more likely to view themselves as individualistic, egocentric, and discrete from society, whereas Easterners are more inclined to view themselves as collectivistic, sociocentric, and related to others or society.

The explanation offered by Varnum et al. (2010) is compatible with the results of cultural priming (Kühnen, Hannover, \& Schubert, 2001; Kühnen \& Oyserman, 2002). Despite the claim of Westerners' individualist culture and Easterners' collectivist culture, it is also plausible that universally, people have both an independent self and an interdependent self (e.g., Hong, Benet-Martinez, Chiu, \& Morris, 2003; Hong, Morris, Chiu, \& Benet-Martinez, 2000; Oyserman, 2011). Cultural priming is assumed to make either independent or interdependent self-construal accessible (Trafimow, Triandis, \& 
Goto, 1991), and there is already established evidence that self-construal can be changed by cultural priming. Assuming that the socially connected and autonomous unique selves are culture based and that both are accessible to the people within a culture, shifts toward one or the other definition of the self can be experimentally induced by priming the corresponding cultural orientation or meaning system. The accessible self-construal affects the style of cognition. For example, Kühnen et al. (2001) reported that participants who were asked to point out the differences between themselves and their friends or parents (primed as independent self-construal) showed a tendency to process stimuli in a manner that was unaffected by the context (analytic cognition), whereas those who were asked to point out the similarities between themselves and their friends or parents (primed as interdependent self-construal) were more apt to engage in context-bound thinking (holistic cognition).

\section{An explanation based on philosophical traditions}

Spencer-Rodgers and colleagues (Spencer-Rodgers, et al., 2009; Spencer-Rodgers, Peng, \& Wang, 2010; Spencer-Rodgers et al., 2004; Spencer-Rodgers, Williams, et al., 2010) emphasize the influence of philosophical tradition on style of thinking. This explanation can coincide with the one that is based on Westerners' individualist culture and Easterners' collectivist culture (Nisbett et al., 2001) and can be regarded as adding the aspect of philosophical tradition to the individualism/collectivism explanation. 
However, it can be regarded as different from the individualism/collectivism explanation. First, she argues that the distinction between linear inference and dialectical inference differs from the distinction in attention between analytic and holistic (e.g., Masuda \& Nisbett, 2001). However, she acknowledge that this distinction is related to those in causal inference (e.g., Morris \& Peng, 1994) and in perception of change (Ji, 2008). She also proposes that this distinction is not strongly related to the one between individualism and collectivism. It was because Spencer-Rodgers et al. (2004) found that Latinos (in the United States), whose cultures are collectivist, did not have contradictory self-views (Church, Alvarez, Katigbak, Mastor, Cabrera, TanakaMatsumi et al., 2012 ; Ma-Kellams et al., 2011; Zell, Su, Li, Ho, Hong, Kumkale et al., 2013). This means that the individualism/collectivism explanation cannot be applied to the cultural difference between Westerners' linear thinking and Easterners' dialectical thinking.

Spencer-Rodgers, Williams et al. (2010) argue that linear thinking has been formed in the tradition of Ancient Greek philosophy (e.g., Aristotle's logic), whereas dialectical thinking has been shaped in the tradition of Ancient Chinese philosophy: Taoism, Confucianism, and Buddhism. The latter is strongly related to Easterners' tendency to view the world as changeable based on the result of an association between general beliefs about contradiction and change (Choi et al., 2007). In particular, Easterners' naïve dialecticism, including their folk beliefs, is rooted in the philosophical 
tradition of the concept of yin (negative aspects of the world) and yang (positive aspects of the world), which is central to Taoism. It is used to describe how polar opposites or seemingly contrary forces are interconnected and interdependent in the real world. It reflects the tradition of Chinese ontology - that the world is constantly changing like the switches between yin and yang and is full of contradictions. This tradition is reflected in the Chinese hesitancy to make final judgments. For instance, in the 2nd century BC, there was a famous story about Sāi Weng’s lost horse in the Huáinánž̌, a classic Chinese book on philosophy that blends Taoist, Confucianist, and Legalist. This story is about an old man, Sāi, who raised horses for a living. He experienced alternating good and bad luck but made no judgment regarding whether each was good or bad. This story provided a proverb, which says that bad luck turns to good and good luck turns to bad, and reflects people's naïve belief that the universe is in flux and is constantly changing.

\author{
AN EXPLANATION BASED ON THE DISTINCTION BETWEEN \\ WESTERNERS' LOW-CONTEXT CULTURE AND EASTERNERS' HIGH- \\ CONTEXT CULTURE
}

\title{
Hall's (1976): A multicultural theoretical lens
}

In regard to the cultural differences in cognition (analytic/holistic), we reject neither the 
explanation of Nisbett et al. (2001) nor the explanation of philosophical tradition; however, we propose another possible explanation based on the distinction between Westerners' low-context culture and Easterners' high-context culture for the cultural differences in thinking (linear/dialectical), following a very brief suggestion by Yama (2018). As will be discussed later, this explanation not only captures the cultural differences in thinking but also has the potential to be developed as a socioecological theory and to explain how each of the philosophical traditions has been shaped. The individualism/collectivism explanation is also related to socioecological approaches, as will be examined later. However, the explanation based on the low-/high-context distinction is associated with a different socioecological approach. In this sense, an explanation based on the framework of the philosophical tradition is insufficient if it does not explain how each philosophical tradition has been shaped by the socioecological conditions.

Hall (1976) introduced a dominant cultural dimension called "context" to explore the relationship between culture and communication. His definition of context is almost identical to that of Nisbett and colleagues (Masuda \& Nisbett, 2001; Nisbett et al., 2001), in the sense that it indicates the relevant information about or stimuli to the target. However, he emphasized its importance in natural communication. Hall's "context dimension" provides a framework that enables people to comprehend communication forms ranging from purely nonverbal, such as hand gestures, body 
language, facial expressions, and tone of voice, to purely verbal aspects, such as written text or spoken words, to achieve meaning as the ultimate goal. Hall (1990) integrated three main concepts: context, information, and meaning. These combined concepts encapsulate context as a system of meaning for information exchange between groups of people or within a group of people. He further argued that context is embedded in information with the purpose to create meanings in a message.

Hall further asserted that in a cultural setting, context and information can also mean different things to different people, especially in different cultures (e.g., Gudykunst \& Ting-Toomey, 1988; Korac-Kakabadse, Kouzmin, Korac-Kakabadse, \& Savery, 2001). In their recent review of such concepts, Kittler, Rygl, and Mackinnon (2011) also synthesized Hall's concept of context as the way in which people screen data, evaluate information, and consequently interpret the meaning from the information that they receive.

Hall also suggested that when a society subscribes to a high-context culture, it puts less emphasis on content. Instead, members of the society sensitize their communication behaviors to what is not spoken or written, and nonverbal cues are then taken seriously. Conversely, people in a low-context society often prefer to rely on communicative behaviors that are content-based (purely informational) (Hall, 2000). In their empirical study, Zakaria and Cogburn (2010)P summarized it as follows: high context is recognized as content independent, while low context is known as context 
independent.

\section{The low-context cultures of Westerners and high-context cultures of Easterners}

Hall (1976) claimed that culture serves as a filter when choosing appropriate objects helped by their context. Context can also be used for communication. In some societies, the members share implicit assumptions to a greater extent than those in other societies. People are in a high-context culture in the former case but a low-context culture in the latter case. People in a high-context culture can interpret messages from others without full descriptions, because implicitly shared information is available for their interpretation. Such shared information is further facilitated by the established relationships among the members in a group. Because effective communication promotes trust between two parties, accurate interpretation based on relationship orientation is made viable.

Conversely, people in a low-context culture need explicitly expressed words for communication because they cannot use implicitly shared information as much as those in a high-context culture. Hence, they rely on content-dependent communication, which is direct and explicit. The information needs to be crystallized and made explicit so that people can draw meaning from it. In such instances, a person may not infer that a diamond ring is often a necessary condition for a marriage proposal unless and until it is verbalized as such. According to Hall (1976; Hall \& Hall, 1990), generally speaking, 
Westerners have a low-context culture, whereas Easterners have a high-context culture. In this sense, the distinction between high-context culture and low-context culture can be regarded as merely one aspect of the individualism/collectivism distinction (Triandis, 1995). However, the proposed context distinction is not based on data about human relationships but on the cultural differences in human communication and the differences in the use of language and the exchange of information. Furthermore, the low-/high-context dimension does not accord perfectly with the individualism/collectivism distinction. According to Hofstede (1980), the countries with the highest individualist culture are the United States, Australia, and the United Kingdom, while those with the lowest individualist culture are some of the Latin American countries (Venezuela, Panama, Ecuador, and Guatemala). Although East Asians, including Japanese, are regarded as having in a collectivist culture, their individuality scores are not very low. However, according to Hall and Hall (1990), Japan is one of the countries with the highest-context culture, while German-speaking countries have the lowest-context culture. The United Kingdom is not a nation with a very low-context culture, although it is a nation with a high individualist culture. We are unable to discuss these groupings in this paper, but we refer to them in order to show that these two dimensions do not accord perfectly here. However, we will discuss the difference between the Japanese and Chinese later in this paper.

There is some evidence that, generally speaking, Westerners have low-context 
cultures, whereas Easterners have high-context cultures. Based on an analysis of websites, Würtz (2006) found that Japanese, Chinese, and Koreans, who are assumed to have high-context cultures, adopted the visual effects offered by the Internet to efficiently convey their messages more than Germans, Americans, and North Europeans, who are assumed to be in low-context cultures, did. However, the crosscultural psychological studies cited as evidence for this are few. For example, Kitayama and Ishii (2002) and Ishii, Reyes, and Kitayama (2003) reported that Americans spontaneously paid more attention to verbal content than to vocal tone, whereas Japanese did more to vocal tone than to verbal content. Although they did not refer to the context distinction, this is evidence that, compared to Americans, Japanese prefer indirect and implicit communication.

\section{An explanation for the cultural differences in thinking}

Although Hall (1976) proposed the distinction between Westerners' high-context culture and Easterners' low-context culture, he provided no explanation for the cultural differences of Westerners' linear thinking and Easterners' dialectical thinking. However, in this paper, his idea is expanded to explain the differences in thinking. As mentioned, it is uncertain whether Easterners actually make a conclusion based on dialectical decisions regarding contradictory opinions more than Westerners do, but they may have a stronger tendency than Westerners to hold a view that the world is contradictory. In 
other words, Easterners have a stronger tendency toward naïve dialecticism, which consists of three principles: contradiction, change, and holism.

The key point is that a low-context situation typically arises when people engage in intercultural communication and interaction (e.g., Ting-Toomey, 1999). Along with this point, Gudykunst (1991) argued that people cannot rely upon their implicit common sense (context) when they engage in cross-cultural communication. They are not confident about how much the hearer shares the knowledge that his or her community members have. Therefore, Langer (1989) argued that mindful communication is needed for intercultural communication to occur. His concept of "mindful" communication can be interpreted as explicitly deliberate and careful communication in which people read others' minds when they lack shared implicit assumptions. According to him, mindfulness includes creating a new category with the marginalization of unclear categories, acceptance of new information, and acceptance of plural ideas with conditions for each idea.

Based on the differences in communication between humans and other primates, Tomasello (2008) proposed that human communication had its evolutionary origins in gesture, not vocalization. Humans used to use nonverbal communication tools, such as gestures, more than modern-day people do, and they could not interpret what others wanted to tell them without context. This kind of communication becomes impossible when people do not share common contexts. In other words, the origin of 
human communication was in a high-context culture. Humans could create a lowercontext culture in which they could engage in mindful communication alongside the evolution of language. People seek more explicit and general rules that can be applied among those who do not share a common context. One classification of rules is between indicative and deontic (e.g., Manktelow \& Over, 1991). The former, which includes logic, is used to describe the world, whereas the latter, which includes social and cultural rules, is used to give people a prescription for behavior. Both kinds of rules are especially necessary when interacting with different cultural groups, as they enable people on both sides to understand the rules. Therefore, the tendency to focus on a single property (Norenzayan et al., 2002) is very adaptive in this situation. With the help of this tendency, people resolve inconsistencies caused by changes. These changes may easily increase in cross-cultural interactions. Therefore, people are adaptive with regard to ontological views, which are opposed to naïve dialecticism. It is plausible that this attitude makes Westerners view the world as less changeable than Easterners do, because the view that the world is changeable prevents people from finding rules or dispositions.

Conversely, it is easy for people who live in a high-context culture and have implicitly shared beliefs to communicate with each other, even if they do not use explicit expressions. Because it is less likely for them to interact with different cultural groups, they need not have explicit rules. This means that they need not focus on a 
single rule, which can possibly be an explicit and universal rule governing cross-cultural interaction. They usually consider many situational factors that become less explicit than is the case when focusing on a single rule or property. They are more likely to encounter inconsistencies because of considered plural factors, because they become more sensitive to the changes caused by these factors and more accepting of the inconsistencies due to their cultural practices, compared to those who are in a lowcontext culture. This can explain Easterners' view that the world is full of contradictions and, thus, their tendency to favor the norm of dialectical thinking.

Furthermore, if there is an apparent contradiction, Easterners believe that it is easier for them to resolve it implicitly using contextual beliefs in a high-context culture. Although we acknowledge that, unlike Hegelian dialecticism, Easterners' naïve dialecticism does not aim to find a middle-way resolution (Wong, 2006), the need to resolve inconsistency is universal (e.g., Festinger, 1957). This is why they believe that they have a better understanding of contradictions than Westerners, and this belief makes it possible for them to have the view that the world is full of contradictions. For instance, people believe that a contradiction can be resolved by these implicitly shared contexts, and thus, they agree with the statement "When I hear two sides of an argument, I often agree with both," which is one of the items on the DSS questionnaire. In the case of proverbs with contradictions (Peng \& Nisbett, 1999), for example, even if they encounter a beautiful girl who says that she is not beautiful, and some argue that 
she is actually proud of her beauty, they may infer that she is attempting to make everyone focus on her; wants someone to deny what she says; and, thus, hopes to show that she is beautiful. Hence, if their inference is based on the implicitly shared social custom, they can resolve the inconsistency such as expressed in the proverb "too humble is half proud." People's implicitly shared beliefs can form the context when communicating, and Easterners utilize context in a high-context culture more than Westerners in a low-context culture. The belief and norm that inconsistencies can be and should be resolved by implicitly shared context make it possible for people to have a view that things are always changing in the world, because they can resolve the inconsistency caused by these changes.

This explanation for the cultural differences in thinking is not based on the differences in communication style but, rather, on the cultural differences in regard to whether people share implicit beliefs. This may cause the differences in their communication styles and thinking style.

\section{SOCIOECOLOGICAL EXPLANATIONS FOR THE CULTURAL}

\section{DIFFERENCES}

\section{The big history}

As mentioned, we do not reject the explanation based on philosophical tradition 
(Spencer-Rodgers, et al., 2004, 2009; Spencer-Rodgers, Peng, et al., 2010; SpencerRodgers, Williams, et al., 2010). However, this explanation is insufficient to explain cultural diversity in a naturalistic sense. In other words, we need to know how such philosophical traditions have been shaped, accepted, and transmitted by socioecological and geographical factors.

These problems are discussed in the big history approach. Originally, the term "big history" means an academic discipline that examines history from the "big bang" of the universe to the present. But, it is also used to focus on human evolution and cultural development from the era of the earliest humans to the contemporary world in the fields of psychology and anthropology. The big history of how contemporary cultural diversity has been shaped starts from the "Out of Africa" migration of Homo Sapiens about 60,000 years ago. There have been some outstanding works on the explanation of cultural diversity and the unbalanced development of civilization, using geographical and ecological factors (e.g., Diamond, 1997), and on the explanation of how contemporary civilizations have been developed (e.g., Harari, 2015).

We examine whether it is possible that the explanation based on the low-/highcontext distinction can be developed as a socioecological theory. Before this, we introduce the approach to find socioecological explanations for the individualism/collectivism distinction. 


\section{The individualism/collectivism distinction}

Regarding the cultural differences discussed in this paper (individualism vs.

collectivism and analytic cognition vs. holistic cognition), the ecological bases for the cultural diversity between individualism and collectivism have been intensively discussed. For example, Berry (1994) pointed out the history from hunter-gatherer society to industrial society and how it is related to individualism or collectivism. As shown below, it was demonstrated that livelihood influences people's cognitive style. Because livelihood is determined by ecological factors and influences human cooperation, these studies are summarized as a socioecological approach to cultural differences (Oishi \& Graham, 2010).

For example, Uskul, Kitayama, and Nisbett (2008) argued that a cognitive style is shaped so that people behave adaptively in their lives or jobs. They reported that in Turkey, herding people, who are assumed to be more socially independent, showed a stronger tendency toward analytic cognition than farmers and fishermen. Herding activities do not require much cooperation but rely on individual decision-making. The individual level of social independence can be an intermediate stage between their independent lifestyle and their analytic cognitive style. Their study shows socioecological factors (livelihood) that influence cognitive style.

Recently, Talhelm, Zhang, Oishi, Shimin, Duan, Lan, and Kitayama (2014) showed that the Chinese from the southern rice-growing area are more holistic in 
cognition and interdependent than the Chinese from the northern wheat-growing area, who are less holistic in cognition and interdependent. These results elaborate a very vague popular belief that hunting nourishes an individualist culture, whereas agriculture develops a collectivist culture. They propose that a history of farming rice makes cultures more interdependent than that of farming wheat and that these agricultural legacies continue to affect people in the modern world. Rice farming requires infrastructure such as flood control and irrigation construction; thus, rice farmers have to be more cooperative than wheat farmers. In short, it depends on the degree of cooperation whether people nourish a collectivist culture.

However, such research comparing rice farmers with wheat farmers is too limited to fully support their claim. Tentatively, it is plausible that whether people shape a collectivist culture depends on whether or not their livelihood requires cooperation. More researches which provide such evidence are needed in the near future.

\section{The low-/high-context distinction}

The explanation based on the low-/high-context distinction also has the potential to be incorporated into the big history approach. However, this possibility has never been discussed extensively. To reiterate, Hall (1976) introduced three main elements to make multicultural-based communication effective: context, information, and meaning. Context shapes the type of information that is needed to produce accurate interpretation 
of meanings. The theory argues that the system of meaning can be looked at based on a continuum that has two extreme points - high- and low-context communication stylesbut adaptation can also take place. The absence of any of these three elements poses challenges for high-context culture to work with low-context culture and vice versa. In support of this, Gallois, Ogay, and Giles (2005) argued that people change their communicative behaviors through adaptation and that the sociohistorical context shapes an individual's initial orientation. Their theory further helps to explain the adaptive communicative behaviors in which individuals engage during their interaction in a multicultural environment: They either converge toward or diverge away from each other.

Based on such theorizing, Gudykunst (1991) further questioned the contextual condition that exists when one communicates with a stranger from a different cultural group - whether or not the individual is able to employ a communication style that is suited to a rich or weak contextual environment? Zakaria and Yusof (2014; in press) asserted that at the inception stage of multicultural collaboration, when communication is challenged, it is difficult for high context people to develop swift trust in strangers. A high-context communication style is reliant on a shared understanding that is based on an established relationship between two people who interpret meanings effectively. As a solution, people are more likely to engage in a low-context style, which is reliant on explicit and transparent messages when communicating with strangers to avoid any 
misunderstanding. The speaker and the listener are in a low-context situation in this case. It is adaptive for people to shape a low-context culture in which it is the norm not to rely on context-dependent style, which is not shared by strangers when they frequently engage in intercultural communication and interaction (e.g., Molinsky, 2007; Ting-Toomey, 1999). Communication with strangers poses challenges in a multicultural environment, in which they need to engage in content-dependent communication as a replacement for a context-dependent communication style (Zakaria \& Cogburn, 2007).

In other words, a multicultural environment is a necessary condition for developing a low-context culture in which people are encouraged to avoid ambiguous expressions that cannot be interpreted without a rich context. Furthermore, Molinsky (2007) introduced a concept called "cross-cultural code switching," which is applicable in the context of the multicultural environment in which communication takes place. This concept is defined as "the act of purposefully modifying one's behavior, in a specific interaction in a foreign setting, to accommodate different cultural norms for appropriate behavior” (p. 623). Given Molinsky's concept, a study by Zakaria (2017) established one emergent pattern of communicative behavior, which she identified as "switching behaviors." People seemed to accommodate the communication styles of others to share information and develop meaningful relationships. As a result, such adaptive behaviors enhance the level of trust among heterogeneous members. Highcontext members tend to be more adaptive, and thus adjust their highly context- 
dependent behaviors to low-context culture, which produces direct and straightforward messages when working with strangers in the early stage of collaboration.

Additional evidence was reported by Rychlowska, Miyamoto, Matsumoto, Hess, Gilboa-Schechtman, Kamble et al. (2015), who demonstrated that people in countries in which historical (cultural) heterogeneity is high need to make explicit facial expressions. Historical heterogeneity (Putterman \& Weil, 2010) is the extent to which a country's contemporary population descends from numerous (vs. few) source countries, and it is generally greater among Western countries. Investigating the explicitness of facial expressions, they gathered data from 32 countries. They reported that the explicitness is determined by historical (cultural) heterogeneity, which is associated with the norm favoring explicit facial expression. Context is less available for people to interpret others' facial expressions in a historically heterogeneous society; hence, they need to make explicit facial expressions. Although the study by Rychlowska et al. (2015) is not on dialectical and/or linear thinking, the principle that ambiguous expression is avoided in a multicultural environment can be applied to the distinction between linear and dialectical thinking. Rychlowska et al. (2015) did not refer extensively to the low-/high-context distinction, and it is clear that shared beliefs (context) are less available for people in historically heterogeneous - in other words, a low-context — cultures. Generally, people in low-context cultures should not use ambiguous expressions for communication. They have to avoid inconsistency without 
resolution.

It has been proposed that multicultural experience enhances dialectical and creative thinking (e.g., Leung, Maddux, Galinsky, \& Chiu, 2008; Paletz et al., 2018). This appears to refute the claim that a multicultural environment shapes a low-context culture and, thus, avoids dialectical thinking. For example, Leung, and Chiu (2010) reported that their participants (European-Americans) showed better creative performance after being exposed to American and Chinese cultures. This result is interpreted as follows: Multicultural experience is likely to make it possible for people to have plural views, and thus, think dialectically (Paletz et al., 2018). However, it is plausible that this dialectical thinking is not the kind of naïve dialecticism that is shared by Easterners but, rather, the kind of Hegelianism that is geared toward the resolution of discrepancies between different views.

Our ancestors lived in a tribal or clan society, in which they often used nonverbal communication tools and shaped a high-context culture. However, when they met and interacted with different cultural groups, they possibly created a low-context culture.

(Figure 1 around here)

Therefore, we assume that originally, human culture was highly contextual, and we point out two necessary conditions for a low-context culture. The first condition is a multicultural environment, as shown in Figure 1. This idea can be in line with the 
socioecological approach because many socioecological factors shape the multicultural environment. For example, if there is an unbalanced distribution of resources (e.g. agricultural products, fishery resources, and natural resources) between different cultural groups, if there are ways (on foot, on horseback, by ship, etc.) for them to move, and if different groups do not have hostile relationships (an environment in which it is advantageous to win zero-sum games), their multicultural interactions with crosscultural communication become active, and, thus, a multicultural environment is likely to be formed. It is then adaptive for people to create a low-context culture. Intercultural interaction also occurs in times of human migration. Most human migration has been caused by socioecological factors, such as climate change.

However, some negative factors prevent the development of a low-context culture. The primary factor is whether the interaction between cultural groups is friendly or hostile. If the interaction is hostile, it is very likely that a low-context culture is not well developed in this multicultural environment — because such a culture is developed so that people from different cultural groups can communicate-and that the interaction will result in war. The interaction is likely to be hostile when trade is not a win-win game but a zero-sum game. The second factor is that if different cultural groups are unified into a monocultural group through the interaction, it is very likely that they will restore a high-context culture. Therefore, the second condition is not to be unified into a monoculture. This cultural unification is more likely when one group is more powerful 
than other groups and has influence over them. There are possible geographical and ecological factors that can satisfy this condition. For example, if cultural interactions occur in a spacious plain with big rivers, it is plausible that different cultural groups will become unified into bigger cultural groups.

This can be applied to an explanation for the cultural differences in philosophical tradition. Both Greek philosophy (Platonism) and Chinese philosophy originate in a time that Karl Jaspers called the Axial Age, when new ways of thinking about religion and philosophy appeared in Persia, India, China, and the Greco-Roman world. Ancient Greece is a typical place that satisfies both conditions. It consisted of small, loosely linked city-states that were not unified, and trade, conflicts, and interactions occurred between them. The proportion of food self-sufficiency in Ancient Athens was low; Ancient Athens could not produce sufficient food for its people. This was both the cause and consequence of intercultural interaction with surrounding countries. We are not certain whether Ancient Greece had a low-context culture (e.g., Nisbett, 2003, proposed that the Ancient Greeks had a remarkable sense of personal agency and were, thus, individualistic), but we know that the Greeks created logic, which consists of a set of rules, to resolve contradiction. This contrasts clearly with the case of China, which was developed in a spacious plain with big rivers that nourished the philosophical tradition of dialecticism. Because of these ecological conditions, the Han Chinese, who lived on the plain, became the most powerful group in China. 
Therefore, although they had interactions with the ethnic groups surrounding them, most of the groups were integrated into the Han Chinese culture (Inoue, 2011). Thus, the Chinese have maintained a high-context culture.

Other factors might satisfy the conditions, but we do not point out and discuss them all in this paper. The geographical and ecological factors are regarded as being at the distal level, according to the terms outlined by Miyamoto (2013), who argued for the importance of considering and analyzing distal-level, proximal-level, and individuallevel factors in seeking an explanation for cultural diversity. Although we do not deny that there are many proximal-level situational factors, we focus on the distinction between multiculture and monoculture and, thus, the distinction between low-context and high-context cultures.

\section{APPLICATIONS OF THE LOW-/HIGH-CONTEXT EXPLANATION TO \\ CULTURAL DIFFERENCES BETWEEN CHINESE AND JAPANESE AND THOSE WITHIN A COUNTRY}

The explanation based on the low-/high-context distinction opens the possibility of providing an explanation for the cultural differences in thinking between Japanese and Chinese. The cultural differences among Easterners and/or among Westerners is a future research topic in this field. The cultural differences in thinking between Japanese and 
Chinese have not been regarded as important nor significant. However, Zhang et al. (2015) found that the mean DSS scores of their Japanese participants were significantly higher than those of their Chinese participants. This means that Japanese have a more dialectical self than Chinese. This result was not coincidental. Unfortunately, the crosscultural studies that investigate the cultural differences in DSS scores between the Japanese and Chinese are few. However, as shown in Table 1, every study indicates that the mean score of the Japanese participants is higher than that of the Chinese participants. But Studies 2 and 3, conducted by Suzuki, Takemura, and Hamamura (2017), do not deal with solely a comparison between the Japanese and Chinese but include data for other countries; hence, we calculated the $t$-value and Cohen's $d$ of each study to compare the Japanese with the Chinese scores. The $t$-test indicated that the Japanese DSS scores were significantly higher than those of Chinese, with the exception of Zell et al.'s data. In short, it is very plausible that the Japanese have a more dialectical self than the Chinese.

(Table 1 around here)

In addition to the DSS data in Table 1, Miyamoto, Knoepfler, Ishii, and Ji (2013) reported that the mean scores for the self-consistency (English \& Chen, 2007) of the Japanese were lower than those of the Americans and Chinese. The index of selfconsistency is designed to indicate the consistency across different relationship contexts. Hence, the index shows that in regard to relationships, the Japanese are more 
dialectical than not only the Americans but also the Chinese.

The explanation that is based on philosophical tradition (e.g., Spencer-Rodgers et al., 2004) is unable to account for the differences between the Japanese and Chinese, because Japanese philosophical tradition is assumed to be transmitted from China. Additionally, the explanation based on the individualism/collectivism distinction (Nisbett et al., 2001; Varnum et al., 2010) does not provide a reason for the differences, because both the Chinese and Japanese cultures are regarded as collectivist.

Rather, this explanation may make an opposing prediction. Hofstede (1980) measured the degree of individuality of each country and found that Japan's individuality index score is higher than that of China. It is uncertain why, but there may be many complex reasons for this. Therefore, the result that the Japanese were more dialectical than the Chinese (Miyamoto et al., 2013; Suzuki et al., 2017; Zhang et al., 2015) is not compatible with the individuality index if the dialecticism is related to collectivism.

A possible explanation is provided by the hypothesis that is based on the low/high-context distinction. One of the indexes of a high-context culture is the use of ellipses in linguistic convention; this refers to the omission from a clause of one or more words that are, nevertheless, understood in the context of the remaining elements, because the use of ellipses is acceptable when the meaning can be recovered based on context. When it is easy for people to access context to recover an omitted part of a 
sentence, the omitted part can be redundant in natural communication. We introduce the findings of an analysis of the Japanese language by Ikegami (2000). According to him, the Japanese language is characterized by the fact that subjects that are considered to be originally indispensable are often omitted not only in everyday conversation but also in formal sentences. This is a notable difference between Japanese and other languages, including the Chinese languages. The omitted subject can be recoverable from its context. Although he does not use the distinction between low-context and high-context culture, it is very plausible that Japanese have a higher-context culture than the Chinese do, because the recoverability is higher in Japanese than in Chinese. The differences in language may influence the cultural differences in thinking between the Japanese and Chinese. However, because the ellipses in the Japanese language may reflect the Japanese high-context culture, it is possible that this culture influences both the dialectical self-concept and the ellipses of the Japanese language. Focusing on the Japanese communication style with the use of ellipses, Rösch and Segler (1987) regarded Japan as one of the highest-context-culture countries.

This analysis is compatible with the claim by Hall and Hall (1990) that Japan is one of the countries with the highest-context culture. The index of historical heterogeneity has not yet been fully investigated; hence, although China's score is the same as that of Japan (Putterman \& Weil, 2010), it is very plausible that the Chinese have experienced cross-cultural communication more than the Japanese. This is because 
Chinese history is characterized as one of interaction (trade and/or wars) with ethnic groups surrounding China and because China has more ethnic groups within it than Japan does. Conversely, the Japanese who have lived on some islands (Japanese archipelago) have been less interactive with ethnic groups than the Chinese. It is plausible that this has made the Japanese nourish a higher-context culture. Because of this, the Japanese may have fostered a different philosophical tradition from the Chinese, and thus, the approach that is based on the philosophical tradition (e.g., Spencer-Rodgers, et al., 2009) may explain the differences in the degree of dialecticism between the Chinese and Japanese. However, this may be a topic of future study.

The explanation that is based on the low-/high-context culture has the potential for not only the differences between the Chinese and Japanese but also the differences within a country. However, although there have been many studies in which analytic and holistic cognition have been contrasted, the studies on dialectical thinking are few. For example, Kitayama, Ishii, Imada, Takemura, and Ramaswamy (2006) compared Japanese who were born and grew up in Hokkaido with non-Hokkaido Japanese. Although ethnic people called Ainu have lived in Hokkaido, it was settled extensively by the Japanese in the early 1870s, and many of the current residents are descendants of the original settlers. They report that Hokkaido students engage in more fundamental dispositional thinking, which is a style of linear thinking, than non-Hokkaido students, and they explain the results in terms of the independent/interdependent distinction. That 
is, as the descendants of the pioneers, Hokkaido students have a more independent self. However, the results can also be explained by the low-/high-context culture distinction. It is plausible that the pioneers who left their traditional village communities created a low-context culture in the new frontier as they interacted with people from different cultures. Generally, as mentioned, it is likely that a low-context culture is created in a multicultural environment, and this cultural change is a result of the settlements and migration caused by social changes, including industrialization. Knight and Nisbett (2007) also reported on the cultural differences within a country. They found that northern Italians performed a categorization task in a more analytical fashion than southern Italians. In other words, northern Italians engaged in more linear thinking. According to Knight and Nisbett, this was because northern Italians were more independent in regard to middle-class social practices. However, again, it is plausible that middle-class people are more likely to be apart from their traditional communities and to nourish a low-context culture.

We discuss whether our explanation can be applied to Middle Eastern and South American countries. Crook, Spencer-Rodgers, and Peng (2014) claimed that Arab people are not dialectical thinkers. Furthermore, Zell et al. (2013) reported that the mean DSS scores of Turkish, Israelis, and South Americans (Argentina, Bolivia, Colombia, and Mexico) were low. Their data and claims were compatible not only with the explanation based on the low-/high-context culture but also with the explanation based 
on the individualism/collectivism distinction, because Arabs, Israelis, Turkish, and South American countries have a collectivist culture.

Most researchers agree that Easterners (Chinese, Japanese, and Koreans) are in the highest-context cultures, whereas Europeans who speak Germanic languages (British, German, Scandinavian, etc.) and are descendants of European immigrants to the United States, Canada, Australia, and New Zealand are in the lowest-context cultures. In fact, other countries or regions are classified by some studies as highcontext cultures and by other studies as a low-context cultures (Kittler et al., 2011). Although no studies investigated the culture of the Arab countries that were listed by Kittler et al. (2011), they introduced two studies dealing with Israel. Rosenbloom and Larsen (2003) classified Israel as a high-context-culture country, whereas Adair (2003) regarded Israel as a low-context-culture country. The former focused on channel communication for business, whereas the latter focused on the everyday communication style. In short, Israel is a lower-context culture country than China, Japan, and Korea, and thus similarly Arab countries are inferred to be, too.

Currently, the explanation that is based on low-/high-context culture may not be able to capture the cultural differences in the dialecticism of all peoples, including Arabs, if we strictly adopt Kitter et al.'s (2011) country classification of low- to highcontext culture. However, we also adopt the dimension of multiculturalism considering the ideas of Ting-Toomey (1999) and Gudykunst (1991). The cultural heterogeneity 
scores of East Asian countries (Japan, Korea, and China) are the lowest in the world (Putterman \& Weil, 2010). However, those of Middle Eastern countries (Israel and Turkey) are not very low. This is because cross-cultural interactions in the Middle East have been more frequent than in East Asia. Therefore, it is plausible that people in the Middle East have a non-dialectical thinking style.

The weakness of the explanation based on the low-/high-context culture is that there are plural measures of its degree (communication style, syntactical structure of language, pragmatic aspects of language, etc.); thus, we are not perfectly able to assign a degree to every country. In this paper, we emphasize the development of multiculturalism to be developed as a socioecological theory, but the micro-process of human communication is also important. This is an issue that will be investigated in the near future.

Furthermore, the distinction between low- and high-context cultures may be related to other dimensions that describe the cultural differences in the world. We briefly point out two dimensions in this paper. The first is relational mobility (Schug, Yuki, \& Maddux, 2010). Relational mobility is high in North America but low in Japan. People in high-relational-mobility cultures are comparatively freer to form new relationships and terminate old ones; hence, social commitments in these cultures are relatively fragile. It is very likely that a low-context culture is created where relational mobility is high. However, the relationship between the two cultural dimensions has not yet been 
investigated. The second dimension is cultural tightness/looseness (Gelfand, Nishii, \& Raver, 2006; Gelfand, Raver, Nishii, Leslie, Lun, Lim et al., 2011). The dimension of cultural tightness/looseness can be defined as the strength of social norms and the degree of sanctioning. Gelfand et al. (2006) gathered data from 33 nations and found that the tightness scores were generally higher in Eastern nations. They proposed that tightness/looseness is part of a complex, loosely integrated system, and they theorized that the strength of social norms and the tolerance of deviant behavior are afforded by numerous distal ecological and human-made societal threats, as well as societal institutions and practices. The higher the societal threats in a nation, the tighter its tightness culture. But, it is uncertain whether people in a high-context culture are more declined to maintain implicit norms than those in a low-context culture. These problems should be investigated in the near future.

Despite these unresolved problems, the idea of the low-/high-context culture is promising in this time of industrialization and globalization. Both industrialization and globalization lead to the formation of multicultural environments, in which people should be better able to create a low-context culture to enhance their mutual understanding. Research on the distinction between low- and high-context cultures is expected to provide solutions to the problems resulting from globalization. As mentioned, mindful communication (Langer, 1989) is needed for intercultural communication. This idea is applied to international business, and Paul, Meyskens, and 
Robbins (2011) proposed that people should have a global mind-set in regard to intercultural communication. This proposed mind-set has two components: crosscultural sensitivity and sensitivity to corporate social performance.

If people fail to create an adaptive low-context culture, it is very plausible that they are helplessly isolated within a multicultural environment. For example, Putnam (2000) pointed out the decline of social capital, which functions in social groups and includes factors such as interpersonal relationships. This is even the case in the United States, which has been regarded as one of the countries with the lowest-context cultures since 1950, when contemporary industrialization started. He described the reduction in all the forms of in-person social intercourse, which Americans used to find, educate, and enrich the fabric of their social lives.

\section{CONCLUSION}

First, we examined whether, as previous studies (e.g., Peng \& Nisbett, 1999) claimed, Easterners are more dialectical in their thinking than Westerners. Reviewing several cross-cultural studies, we provisionally conclude that, although it is uncertain whether dialectically, Easterners agree or disagree with contradictory opinions more than Westerners, they may have a more dialectical self-concept and are more dialectical in regard to emotion. 
Second, we examined two existing explanations for the cultural differences in thinking. The first is based on the distinction between Westerners' analytic cognition and Easterners' holistic cognition, which is explained by the individualism/collectivism distinction (Nisbett, 2003; Nisbett et al., 2001; Varnum et al., 2010). The individualism/collectivism distinction may be valid in terms of explaining the cultural differences between Westerners' analytic cognition and Easterners' holistic cognition. However, because of the finding that Latinos are collectivist but are not dialectical (Spencer-Rodgers et al., 2004), Spencer-Rodgers and colleagues (Spencer-Rodgers, et al., 2009; Spencer-Rodgers, Peng, et al., 2010; Spencer-Rodgers, Williams, et al., 2010) abandoned the explanation based on the individualism/collectivism distinction, arguing that linear thinking has been formed in the tradition of Ancient Greek philosophy, whereas dialectical thinking has been shaped in the tradition of Ancient Chinese philosophy. Easterners' naïve dialecticism is rooted in the philosophical tradition of the concept of yin and yang.

Third, we do not reject the explanations in the previous studies. However, we propose another possible explanation based on the distinction between Westerners' lowcontext culture and Easterners' high-context culture (Hall, 1976). Easterners need not seek a more explicit and general rule that can be applied among those who do not share a common context, and they may believe that they can resolve an inconsistency using context, and they have a belief that they can resolve it in a high-context culture. 
Furthermore, this explanation has the potential to be developed as a socioecological theory and can, thus, be incorporated into a grand big history theory. We propose geographical and ecological conditions for a low-context culture: a multicultural environment and not to be unified into a monoculture. These can be applied to the explanation for two kinds of philosophical traditions: Ancient Greek and Ancient Chinese.

Finally, we remarked on the cultural differences between Chinese and Japanese. It is plausible that Japanese are more dialectical thinkers than Chinese based on the DSS index. This difference cannot be explained by the explanation based on the individualism/collectivism distinction nor by the explanation based on the philosophical tradition. It is only the explanation that is based on the low-/high-context distinction that can capture the difference. In line with this, the cultural differences among Easterners (Chinese and Japanese) and within a country are also issues to be discussed in the framework of the low-/high-context culture in the near future. Furthermore, we tried to apply this framework to the cultural differences within a country and those related to non-Easterners and non-Westerners. These should be extensively discussed in the near future.

\section{REFERENCES}


Adair, W. L. (2003). Integrative sequences and negotiation outcome in same-and mixed culture negotiations. International Journal of Conflict Management, 14, 273-296. doi.org/10.1108/eb022902

Atran, S. \& Medin, D. L. (2008). The native mind and the cultural construction of nature. Cambridge, MA: MIT Press.

Bagozzi, R. P., Wong, N., \& Yi, Y. (1999). The role of culture and gender in the relationship between positive and negative affect. Cognition and Emotion, 13, 641672. doi.org/10.1080/026999399379023

Berry, J. W. (1994). Ecology of individualism and collectivism. In U. Kim, H. C. Triandis, Ç. Kagitçibasi, S. C. Choi, \& G.Yoon (eds.), Individualism and collectivism. Thousand Oaks, CA: Sage Publications. pp. 77-84.

Boucher, H. C., Peng, K., Shi, J., \& Wang, L. (2009). Culture and implicit self-esteem: Chinese are "good" and "bad" at the same time. Journal of Cross-Cultural Psychology, 40, 24-44. doi: 10.1177/0022022108326195

Buchtel, E. E. \& Norenzayan, A. (2008). Which should you use, intuition or logic? Cultural differences in injunctive norms about reasoning. Asian Journal of Social Psychology, 11, 264-273. doi.org/10.1111/j.1467-839X.2008.00266.x

Choi, I., Dalal, R., Kim-Prieto, C., \& Park, H. (2003). Culture and judgment of causal relevance. Journal of Personality and Social Psychology, 84, 46-59. doi: 
Choi, I., Koo, M., \& Choi, J. A., (2007). Individual differences in analytic versus holistic thinking. Personality and Social Psychology Bulletin, 33, 691-705. doi.org/10.1177/0146167206298568

Choi, I. \& Nisbett, R. E. (1998). Situational salience and cultural differences in the correspondence bias and actor-observer bias. Personality and Social Psychology Bulletin, 24, 949-960. doi.org/10.1177/0146167298249003

Choi, I. \& Nisbett, R. E. (2000). Cultural psychology of surprise: Holistic theories and recognition of contradiction. Journal of Personality and Social Psychology, 79, 890-905. doi.org/10.1037/0022-3514.79.6.890

Choi, I., Nisbett, R. E., \& Norenzayan, A. (1999). Causal attribution across cultures: Variation and universality. Psychological Bulletin, 125, 47-63. doi:00332909/99/S3.00.

Chomsky, N. (1957). Syntactic structures. Mouton, The Hague.

Church, A. T., Alvarez, J.M., Katigbak, M. S., Mastor, K. A., Cabrera, H. F., TanakaMatsumi, J., ...Buchanan, A. L. (2012). Self-concept consistency and short-term stability in eight cultures. Journal of Research in Personality, 46, 556-570. doi:10.1016/j.jrp.2012.06.003.

Crook, S., Spencer-Rodgers, J., \& Peng, K. (2014). Dialectical thinking in Arabic-, English-, and Chinese-Speaking nations. Approaches: Revue des Sciences Humaines, 14, 12-27. 
Diamond, J. (1997). Guns, germs, and steel. New York: W. W. Norton \& Company.

English, T., \& Chen, S. (2007). Culture and self-concept stability: Consistency across and within contexts among Asian Americans and European Americans. Journal of Personality and Social Psychology, 93, 478-490. doi.org/10.1037/00223514.93.3.478

Festinger, L. (1957). A theory of cognitive dissonance. Stanford, CA: Stanford University Press.

Friedman, M., Chen, H-C., \& Vaid, J. (2006). Proverb preferences across cultures: Dialecticality or poeticality? Psychonomic Bulletin \& Review, 13, 353-359. doi:10.3758/BF03193856

Gallois, C., Ogay, T., \& Giles, H. (2005). Communication accommodation theory: A look back and a look ahead. In W. B. Gudykunst (ed.). Theorizing about intercultural communication. Thousand Oaks: Sage Publication. Pp. 121-148.

Gelfand, M. J., Nishii, L. H., \& Raver, J. L. (2006). On the nature and importance of cultural tightness-looseness. Journal of Applied Psychology, 91, 1225-1244. doi: 10.1037/0021-9010.91.6.1225

Gelfand, M. J., Raver, J. L., Nishii, L., Leslie, L. M., Lun, J., Lim, B. C.,...Yamaguchi, S. (2011). Differences between tight and loose cultures: A 33-nation study. Science, 332, 1100-1104. doi: 10.1126/science.1197754

Gudykunst, W. B. (1991). Bridging differences: Effective intergroup communication. 
Newbury Park, CA: Sage Publications.

Gudykunst, W. B., \& Ting-Toomey, S. (1988). Culture and interpersonal communication. Thousand Oaks, CA: Sage Publications.

Hall, E. T. (1976). Beyond culture. Garden City, NJ: Anchor Books/Doubleday.

Hall, E. T. (2000). Context and meaning. In L. A. Samovar \& R. E. Porter (eds.), Intercultural communication: A reader, $9^{\text {th }}$ ed. Belmont, CA: Wadsworth Publishing, pp.34-43.

Hall, E. T., \& Hall, M. R. (1990). Understanding cultural differences. Yarmouth, ME: Intercultural Press.

Harari, Y. N. (2015). Sapiens: A brief history of humankind. New York: Harper Collins Publishers.

Hofstede, G. (1980). Culture's consequences: International differences in work-related values. Beverly Hills, CA: Sage.

Hong, Y.-Y., Benet-Martinez, V., Chiu, C.-Y., \& Morris, M. (2003). Boundaries of cultural influence: Construct activation as a mechanism for cultural differences in social perception. Journal of Cross-Cultural Psychology, 34, 453-464. doi.org/10.1177/0022022103034004005

Hong, Y.-Y., Morris, M. W., Chiu, C.-Y., \& Benet-Martinez, V. (2000). Multicultural minds: A dynamic constructivist approach to culture and cognition. American Psychologist, 55, 709-720. doi.org/10.1037/0003-066X.55.7.709 
Ikegami, Y. (2000). Invitation to theories of Japanese. Tokyo: Kodansha. (in Japanese)

Inoue, T. (2011). How did Han people integrate non-Han people regarded as barbarians into greater China? Historical Journal, 733, 57-70. (in Japanese)

Ishii, K., Reyes, J. A., \& Kitayama, S. (2003). Spontaneous attention to word content versus emotional tone: Differences among three cultures. Psychological Science, 14, 39-46. doi.org/10.1111/1467-9280.01416

Ji, L.-J. (2008). The leopard cannot change his spots, or can he? Culture and the development of lay theories of change. Personality and Social Psychology Bulletin, 34, 613-622. doi.org/10.1177/0146167207313935

Ji, L.-J., Nisbett, R. E., \& Su, Y. (2001). Culture, change, and prediction. Psychological Science, 12, 450-456. doi:10.1111/1467-9280.00384

Ji, L.-J., Peng, K., \& Nisbett, R. E. (2000). Culture, control, and perception of relationships in the environment. Journal of Personality and Social Psychology, 78, 943-955. doi.org/10.1037/0022-3514.78.5.943

Kitayama, S \& Ishii, K. (2002). Word and voices: Spontaneous attention to emotional speech in two cultures. Cognition and Emotion, 16, 29-59. doi.org/10.1080/0269993943000121

Kitayama, S., Ishii, K., Imada, T., Takemura, k., \& Ramaswamy, J. (2006). Voluntary settlement and the spirit of independence: Evidence from Japan's "Northern Frontier”. Journal of Personality and Social Psychology, 91, 369-384. 
doi:10.1037/0022-3514.91.3.369

Kittler, M. G., Rygl, D., \& Mackinnon, A. (2011). Beyond culture or beyond control? Reviewing the use of Hall's high-/low-context concept. International Journal of Cross Cultural Management, 11, 63-82. doi.org/10.1177/1470595811398797

Knight, N. \& Nisbett, R.E. (2007). Culture, class and cognition: Evidence from Italy. Journal of Cognition and Culture, 7, 283-291. doi: 10.1163/156853707X208512

Korac-Kakabadse, N., Kouzmin, A., Korac- Kakabadse, A., \& Savery, L. (2001). Lowand high-context communication patterns: Towards mapping cross-cultural encounters. Cross Cultural Management, 8, 3-24. doi.org/10.1108/13527600110797218

Kühnen, U., Hannover, B., \& Schubert, B. (2001). The semantic-procedural interface model of the self: The role of self-knowledge for context-dependent versus contextindependent modes of thinking. Journal of Personality and Social Psychology, 80, 397-409. doi.org/10.1037/0022-3514.80.3.397

Kühnen, U., \& Oyserman, D. (2002). Thinking about the self-influences thinking in general: Cognitive consequences of salient self-concept. Journal of Experimental Social Psychology, 38, 492-499. doi.org/10.1016/S0022-1031(02)00011-2

Langer, E. (1989). Mindfulness. Reading, MA: Addison-Wesley.

Leung, A. K. Y., \& Chiu, C.-Y. (2010). Multicultural experience, idea receptiveness, and creativity. Journal of Cross-Cultural Psychology, 41,723-741. 
doi.org/10.1177/0022022110361707

Leung, A. K. Y., Maddux, W. W., Galinsky, A. D., \& Chiu, C.-Y. (2008). Multicultural experience enhances creativity: The when and how. American Psychologist, 63, 169-181. doi.org/10.1037/0003-066X.63.3.169

Ma-Kellams, C., Spencer-Rodgers, J., \& Peng, K. (2011). I am against us?: Unpacking cultural differences in ingroup favoritism via dialecticism. Personality and Social Psychology Bulletin, 37, 15-27. doi:10.1177/0146167210388193

Manktelow, K. I., \& Over, D. E. (1991). Social roles and utilities in reasoning with deontic conditions. Cognition, 39, 85-105. doi.org/10.1016/0010-0277(91)90039-7

Markus, H. R. and Kitayama, S. (1991). Culture and the self: Implications for cognition, emotion and motivation. Psychological Review, 98, 224-253.

Masuda, T., \& Nisbett, R. E. (2001). Attending holistically versus analytically: Comparing the context sensitivity of Japanese and Americans. Journal of Personality and Social Psychology, 81, 922-934. doi.org/10.1037/00223514.81.5.922

Mercier, H., Yama, H., Kawasaki, Y., Adachi, K., \& Van der Henst, J-B. (2012). Is the use of averaging in advice taking modulated by culture? Journal of Cognition and Culture, 12, 1-16. doi: 10.1163/156853712X633893

Mercier, H., Zhang, J., Qu, Y., \& Lu, P., \& Van der Henst, J-B. (2015). Do Easterners and Westerners treat contradiction differently? Journal of Cognition and Culture, 
15, 45 - 63. doi:10.1163/156853712X633893

Miyamoto, Y. (2013). Culture and analytic versus holistic cognition: Toward multilevel analysis of cultural influences. Advances in Experimental Social Psychology, 47, 131-188. doi.org/10.1016/B978-0-12-407236-7.00003-6

Miyamoto, Y., Knoepfler, C. A., Ishii, K., \& Ji, L.-J. (2013). Cultural variation in the focus on goals versus processes of actions. Personality and Social Psychology Bulletin, 39, 707-719. doi.org/10.1177/0146167213483579

Miyamoto, Y., Uchida, Y., \& Ellsworth, P. C. (2010). Culture and mixed emotions: Cooccurrence of positive and negative emotions in Japan and the United States. Emotion, 10, 404-415. doi.org/10.1037/a0018430

Molinsky, A. (2007). Cross-cultural code switching: The psychological challenges of adapting behavior in foreign cultural interactions. Academy of Management Review, 32, 622-640. doi.org/10.5465/amr.2007.24351878

Morris, W. M., \& Peng, K. (1994). Culture and cause: American and Chinese attributions for social and physical events. Journal of Personality and Social Psychology, 67, 949-971.

Na, J., Grossmann, I., Varnum, M. E. W., Kitayama, S., Gonzalez, R., \& Nisbett, R. (2010). Cultural differences are not always reducible to individual differences. Proceedings of the National Academy of Science of the United States of America, 107, 6192-6197. doi.org/10.1073/pnas.1001911107 
Nisbett, R. E. (2003). The geography of thought: How Asians and Westerners think differently... and why. New York: The Free Press.

Nisbett, R. E., Peng, K., Choi, I., \& Norenzayan, A. (2001). Culture and systems of thought: Holistic versus analytic cognition. Psychological Review, 108, 291-310. doi:10.1037/0033-295X.108.2.291

Norenzayan, A., \& Heine, S. J. (2005). Psychological universals: What are they and how can we know? Psychological Bulletin, 131, 763-784. doi.org/10.1037/00332909.131.5.763

Norenzayan, A., Smith, E. E., Kim, B. J., \& Nisbett, R. E. (2002). Cultural preferences for formal versus intuitive reasoning. Cognitive Science, 26, 653-684. doi:10.1207/s15516709cog2605_4

Oishi, S., \& Graham, J. (2010). Social ecology: Lost and found in psychological science. Perspectives on Psychological Science, 5, 356-377. doi.org/10.1177/1745691610374588

Oyserman, D. (2011). Culture as situated cognition: Cultural mindsets, cultural fluency, and meaning making. European Review of Social Psychology, 22, 164-214. doi.org/10.1080/10463283.2011.627187

Paletz, S. B. F., Bogue, K., Miron-Spektor, E., \& Spencer-Rodgers, J. (2018). Dialectical thinking and creativity from many perspectives: Contradiction and tension. In J. Spencer-Rodgers \& K. Peng (eds.), The psychological and cultural 
foundations of East Asian cognition. New York: Oxford University Press. Pp. 267308.

Peng, K., \& Nisbett, R. E. (1999). Culture, dialectics, and reasoning about contradiction. American Psychologist, 54, 741-754. doi:10.1037/0003066X.54.9.741

Paul, K., Meyskens, M., \& Robbins, S. (2011). Components of a global mindset: corporate social responsibility and cross-cultural sensitivity. Journal of International Business and Cultural Studies, 5, 1-18.

Putnam, R. D. (2000). Bowling alone: The collapse and revival of American community. NY: Simon \& Schuster.

Putterman, L, \& Weil, D. N. (2010). Post-1500 Population flows and the long run determinants of economic growth and Inequality. The Quarterly Journal of Economics, 125, 1627-1682. doi.org/10.1162/qjec.2010.125.4.1627

Rösch, M., \& Segler, K. G. (1987). Communication with Japanese. Management International Review, 27, 56-67.

Rosenbloom, B., \& Larsen, T. (2003). Communication in international business-tobusiness marketing channels: Does culture matter? Industrial Marketing Management, 32, 309- 315. doi:10.1016/S0019-8501(01)00202-4

Rychlowska, M., Miyamoto, Y., Matsumoto, D., Hess, U., Gilboa-Schechtman, E., Kamble, S.,... Niedenthal, P. M. (2015). Heterogeneity of long-history migration 
explains cultural differences in reports of emotional expressivity and the functions of smiles. Proceedings of National Academy of Sciences of the United States of America, 112, 2429-12436. doi.org/10.1073/pnas.1413661112

Schug, J., Yuki, M., \& Maddux, W. (2010). Relational mobility explains between- and within-culture differences in self-disclosure to close friends. Psychological Science, 21, 1471-1478. doi.org/10.1177/0956797610382786

Spencer-Rodgers, J., Boucher, H. C., Mori, S. C., Wang, L., \& Peng, K. (2009). The dialectical self-concept: Contradiction, change, and holism in East Asian Cultures. Personality and Social Psychological Bulletin, 35, 29-44. doi:10.1177/0146167208325772

Spencer-Rodgers, J., Peng, K., \& Wang, L. (2010). Naïve dialecticism and the cooccurrences of positive and negative emotions across cultures. Journal of CrossCultural Psychology, 41, 109-115. doi: 10.1177/0022022109349508

Spencer-Rodgers, J., Peng, K., Wang, L., \& Hou, Y. (2004). Dialectical self-esteem and East-West differences in psychological well-being. Personality and Social Psychological Bulletin, 30, 1416-1432. doi:10.1177/0146167204264243

Spencer-Rodgers, J., Williams, M., \& Peng, K. (2010). Cultural differences in expectations of change and tolerance for contradiction: A decade of empirical research. Personality and Social Psychology Review, 14, 296-312. doi:10.1177/1088868310362982 
Suzuki, S., Takemura, K., \& Hamamura, T. (2017). Cultural differences in dialecticism. Unpublished data.

Talhelm, T., Zhang, X., Oishi, S., Shimin, C., Duan, D., Lan, X., \& Kitayama, S. (2014). Large-scale psychological differences within China explained by rice versus wheat agriculture. Science, 344, 603-608. doi: 10.1126/science.1246850

Ting-Toomey, S. (1999). Communicating across cultures. New York: Guilford Press.

Tomasello, M. (2008). Origins of human communication. Cambridge, MA: MIT Press.

Trafimow, D., Triandis, H. C., \& Goto, S. G. (1991). Some tests of the distinction between the private self and the collective self. Journal of Personality and Social Psychology, 60, 649-655. doi.org/10.1037/0022-3514.60.5.649

Triandis, H. C. (1995). Individual and collectivism. Boulder, CO: Westview Press.

Uskul, A. K., Kitayama, S., \& Nisbett, R. E. (2008). Ecocultural basis of cognition: Farmers and fishermen are more holistic than herders. Proceedings of the National Academy of Science of the United States of America, 105, 8552-8556. doi/10.1073/pnas.0803874105

Varnum, M. E. W., Grossman, I., Kitayama, S. \& Nisbett, R.E. (2010), The origin of cultural differences in cognition: The social orientation hypothesis. Current Direction in Psychological Science, 19, 9-13. doi.org/10.1177/0963721409359301

Wong, W.-C. (2006). Understanding dialectical thinking from a cultural-historical perspective. Philosophical Psychology, 19, 239-260. 
doi.org/10.1080/09515080500462420

Würtz, E. (2006). Intercultural communication on web sites: A cross-cultural analysis of web sites from high-context cultures and low-context cultures. Journal of Computer-Mediated Communication, 11, 274-299. doi:10.1111/j.10836101.2006.00013.x

Yama, H. (2018). Thinking and reasoning across cultures. In L. J. Ball \& V. A. Thompson (eds.), The Routledge international handbook of thinking and reasoning. Oxon, UK \& New York: Routledge, Pp. 624-638.

Yama, H., Manktelow, K. I., Mercier, H., Van der Henst, J-B., Do, K. S., Kawasaki, Y., \& Adachi, K. (2010). A cross-cultural study of hindsight bias and conditional probabilistic reasoning. Thinking and Reasoning, 16, 346-371. doi:10.1080/13546783.2010.526786

Zakaria, N. (2017). Emergent patterns of switching behaviors and intercultural communication style of global virtual teams during distributed decision making. Journal of International Management, 23, 350-366. dx.doi.org/10.1016/j.intman.2016.09.002

Zakaria, N. \& Cogburn, D. L. (2010). Context-dependent vs. content-dependent: An exploration of the cultural behavioural patterns of online intercultural communication using E-mail. International Journal of Business and Systems Research, 4, 330-347. doi.org/10.1504/IJBSR.2010.032954 
Zakaria, N., \& Yusof, S. A. M. (2014). Can we count on you at a distance? The impact of culture on formation of swift trust within global virtual teams. In R. L. Griffith, \& J. L. Wildman (eds.). Leading global teams: Translating the multidisciplinary science to practice. New York: Springer, Pp. 253-268.

Zakaria, N., \& Yusof, S. A. M. (in press). Crossing cultural boundaries using the internet: Toward building a model of swift trust formation in global virtual teams. Journal of International Management. doi.org/10.1016/j.intman.2018.10.004

Zell, E., Su, R, Li, H., Ho, M-H. R., Hong, S., Kumkale, T.,...Albarracín, D. (2013). Cultural differences in attitudes toward action and inaction: The role of dialecticism. Social Psychological and Personality Science, 4, 521-528. doi.org/10.1177/1948550612468774

Zhang, B., Galbraith, N., Yama, H., Wang, L., \& Manktelow. K. I. (2015). Dialectical thinking: A cross-cultural study of Japanese, Chinese, and British students. Journal of Cognitive Psychology, 27, 771-779. doi.org/10.1080/20445911.2015.1025792 
TABLE 1

Mean scores of the Dialectical Self Scale of Japanese and Chinese.

\begin{tabular}{|c|c|c|c|c|c|}
\hline & & Japanese & Chinese & $t$-value & Cohen's $d$ \\
\hline Church et al. (2012) & & $4.39(.63)$ & $4.22(.63)$ & $t=2.76$ & $d=.27$ \\
\hline Participants & & $(\mathrm{n}=191)$ & $(n=233)$ & $\mathrm{p}<.01$ & \\
\hline (University students) & & & & & \\
\hline Suzuki et al. (2017) & Exp.1 & $4.06(.41)$ & $3.91(.34)$ & $t=6.29$ & $d=.40$ \\
\hline Participants (Adults) & & $(n=500)$ & $(n=500)$ & $\mathrm{p}<.01$ & \\
\hline & Exp.2 & $4.09(.40)$ & $3.89(.33)$ & $t=5.86$ & $d=.54$ \\
\hline & & $(n=200)$ & $(n=300)$ & $\mathrm{p}<.01$ & \\
\hline & Exp.3 & $4.23(.39)$ & $3.88(.39)$ & $t=12.68$ & $d=.90$ \\
\hline & & $(n=400)$ & $(n=400)$ & $\mathrm{p}<.01$ & \\
\hline Zell et al. (2013) & & $4.19(.57)$ & $4.11(.43)$ & $t=1.47$ & $d=.15$ \\
\hline Participants (Universit & & $(\mathrm{n}=172)$ & $(\mathrm{n}=288)$ & n.s. & \\
\hline students) & & & & & \\
\hline Zhang et al. (2015) & & $4.37(.44)$ & $4.09(.43)$ & $t=5.24$ & $d=.64$ \\
\hline Participants (High sch & 1 and & $(n=145)$ & $(\mathrm{n}=119)$ & $\mathrm{p}<.01$ & \\
\hline
\end{tabular}

Note. Each SD and number of participants is in the parenthesis of each cell. Church et al. (2012) used a shorter version of DSS. Suzuki, Takemura, and Hamamura (2017) did not publish the results because of the low alpha-values of the Chinese data (.50-.66). (This indicates that the dialectical self of Chinese may have plural dimensions.) 


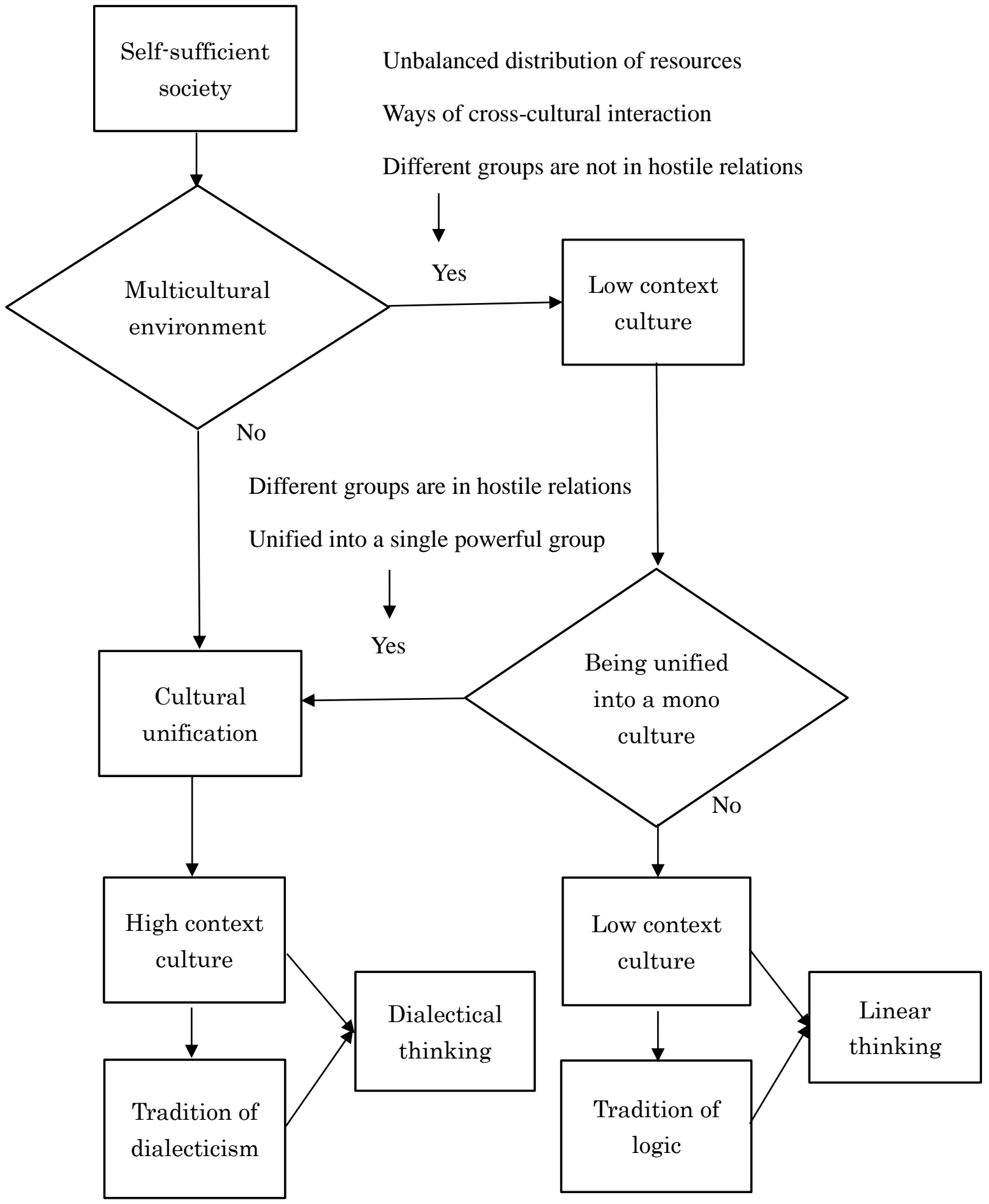


Running Head: CULTURE AND THINKING

Figure 1. A model for the explanation of cultural differences in thinking from the geographical and ecological level to each thinking style. 